\title{
LA ORGANIZACION MUNICIPAL EN LOS ESTADOS AUTORITARIOS
}

\begin{abstract}
$\boldsymbol{E}_{\mathrm{N}}$
el sistema estatal, los órganos municipales no gozan de autarquía; son más bien órganos de Estados, y de Estados fuertes, de suerte que propenden al unitarismo y a la uniformidad.

Italia, Alemania: he ahí los prototipos de la estatificación de los órganos locales-Portugal es una excepción, como veremos-, no como núcleos primordiales del Estado, sino como órganos periféricos de éste, si bien con un mayor margen de autonomía en Alemania que en Italia, o mejor diremos, con un mayor margen de descentralización administrativa funcional, no en cuanto a la designación de sus componentes.
\end{abstract}

\section{a) Italia}

El órgano corporativo municipal en Italia es meramente consultivo, y en la Consulta, sus miembros son designados por los Prefectos de las Provincias, a propuesta en terna de las Asociaciones sindicales legalmente reconocidas (1).

El Podestá-que designan los Prefectos-es el órgano local que centraliza las funciones normativas, administrativas y ejecutivas de los Municipios italianos, atribuídas, por la ley reformada de fecha de 4 de febrero de 1915 (2), al antiguo Consejo comunal-Junta municipal-y al Alcalde-(Sindaco) (3)-, reservándose a la Consulta facultades estrictamente asesoras e informativas.

Las instituciones locales centralizadas responden a una necesidad del momento histórico que las Naciones atraviesan de adjudicar el

(1) Enrico Gatta, "Il nuovo testo unico delle legge comunale e provinciale", mayo, 1934, pág. 304. Con anterioridad a la reforma del $R$. $D$. de 3 de marzo 1934, núm. 383, en las poblaciones de más de 100.000 habitantes los Consejeros eran designados por el Ministerio del Interior. Cfr. texto citado, $g$ Ausonio de Barbieri, "Diritto generale degli enti locale", 1930, pág. 96.

(2) La reforma se hizo por $R$. D. de 30 de diciembre de 1923 , num. 2.839.

(3) Ausonio de Barbieri, Ob. cit.; pág. 94. 
poder local a una sola persona, que esté por encima de las pasiones de las partes, y vigile por la observancia de las leyes (1).

Así el Podestá es el órgano que retiene todas las facultades normativas y administrativas, autoridad local a quien compete la iniciativa y la dirección de los intereses exclusivos de la localidad (2), concurriendo, sin embargo, en algunas gestiones administrativas con el Secretario del Municipio.

A la Consulta le compete única y simplemente la de asesorar al Podestá y al Secretario municipal. Ni por la ley que estableció la Consulta en poblaciones de menos de 5.000 habitantes, de 4 de febrero de 1926 (art. 5..$^{\circ}$ ), ni por el R. D. que la hizo extensiva a todos los demás, 3. de septiembre de 1926 (arts. $2 .^{\circ}$ y 9..$^{\circ}$ ), se preceptuaba-era tan sólo facultativa-para poblaciones de menos de 20.000 habitantes la audiencia de la Consulta, salvo para la confección del presupuesto que hubiera de regir anualmente en el Municipio, la aprobación de créditos que comprometieran presupuestos durante más de cinco años, la contratación de empréstitos, la imposición de tributos, la enajenación, la municipalización directa de los servicios públicos. En las poblaciones de 20.000 a 100.000 habitantes, o de menos de 20.000 , capitales de provincias, la audiencia de la Consulta era obligatoria para mayor número de casos (3). Se concedió menos intervención asesora en los de más de 100.000 habitantes.

La competencia asesora de la Consulta se uniforma más tarde para todos los Municipios, manteniéndose la que asume dicho órgano en poblaciones de más de 20.000 habitantes y menos de 100.000 para la generalidad de ellos, y aumentándose en otros muchos casos: adquisición de acciones industriales y bienes inmuebles, litigios, tran. saciones, arriendo de inmuebles por más de diez años, aprobación de planes de extensión de vías y proyectos de apertura y de construcción de las mismas; reglamentación del uso de los bienes comunales, de higiene, policía local y lo concerniente a las instituciones que pertenecen al Común, y ordenamiento jurídico del funcionario (4).

(1) Fassio, "El Podesta e le sue atribuzioni", págs. 11 y siguientes.

(2) Fassio, "Il Podesta e le sue atribuzioni", cap. I, págs. 30 y siguientes, "La Funzione del Podesta"; Cfr. Tambaro, "Diritto amministrativo", 1930, pagina 166; Michele la Torre, "Nozioni di Diritto" amministrativo", 1933, pag. 128.

(3) Ausonio de Barbieri Ob. cit., págs. 97 y 98; Echmann, "El Estado fascista en Italia", trad. española, págs. 88 y 89 ; Cons. Giovanni de Gennaro, "Caratterer organico representativo delle consulte municipale", Rivista de Diritto pubblico, 1932, pags. 101 a 114; Michele la Torre, Ob. cit., pag. 129.

(4) Enrico Gatta, "El nuevo texto...", cit. págs. 305 y 306 . La Consulta se constituye con un numero de miembros no inferior a diez y no superior a 24 en poblaciones inferiores a 100.000 habitantes; no inferior a 24 y no superior a 40 en otros casos. (Tambaro, Ob. cit., pág. 168.) 
El Estado italiano, al aumentar las funciones de la Consulta, se conduce por los cauces de una asunción consultiva en la gestión municipal; inicia el camino de rectificación de la hipertrofia estatal, para volver, a buen seguro, a implantar la autonomía en los Municipios y a restaurar las funciones administrativas de un órgano colegiado de representación corporativa, no muy numeroso, pero suficiente para permitir una división del trabajo con el órgano unipersonal y principal del Municipio: el Podestá.

\section{b) Alemania}

Existía en los Municipios de muchos países alemanes, al lado de una amplia Asamblea deliberativa o Gran Consejo municipal y del Burgomaestre, un órgano administrativo colegial (el Magișrat), Gestor de la Administración local y órgano ejecutivo, elegido por la Asamblea municipal, integrado por el Burgomaestre (Bürgemeister, Alcalde de la ciudad), y en ciertos casos un segundo Burgomaestre, profesional y director técnico de los servicios administrativos, y de un número de consejeros municipales retribuídos, que variaba en las diversas legislaciones de los países, y atendiendo en cada país al número de habitantes de los Municipios, como variaba en los distintos países las funciones colegiadas, hasta el punto de establecer la distinción entre funciones del Magisrat, como Cuerpo, de la de algunos de sus miembros, como órganos profesionales o directores técnicos de los servicios públicos que poseían en algunas ciudades, por ejemplo, en la de Baviera, sin mengua de las atribuciones jerárquicas del Magisrat y de la Asamblea municipal (1), órgano éste cuyo poder tenía su origen en el Cuerpo electoral del Concejo que regían.

La administración de las ciudades de Prusia se presentaba, antes del advenimiento del nacional-socialismo, bajo la forma de Magisrat o de Burgomaestre-elegidos por la Asamblea de representantes municipales (Stadverordnetenversammlung) 一, asumiendo entonces éste las funciones administrativas, no las meramente ejecutivas y presidenciales, encomendadas, en todo caso, al Burgomaestre, vértice de la pirámide administrativa (2). Regía el Magisrat (3), constituído con

(1) Delbez, "Le régime municipal Allemand" (Rovue de Droit public., 1930. págs. 5 y siguientes); Walter Jellinek, "Werwaltungsrecht", 1929, págs. 66 y siguientes.

Cfr. Piloty Schneider, "Grundriss der Werwaltungsrecht in Bayern und den deutschen Reiche", 1927, págs. 71 y siguientes.

(2) A. Hensel "Kommunalrecht und Kommunatpolitik in Deustchland", 1928 , págs. 79 y siguientes.

(3) Sintetiza Posada en "El Gobierno de la ciudad moderna". 1927, página 216, la estructura y el funcionamiento regulares del Magisrat del periodo :orrespondiente a la vigencia de la Constitución weimeriana, con las siguientes 
la contextura expresada anteriormente, en la Prusia alta, en Hannover y en algunas otras provincias. El régimen de Burgomaestre, o de administración unipersonal, en la provincia del Rhin, auxiliado por los adjuntos (Beigeordnete) (1). En este régimen el Burgomaestre era remunerado.

La Administración actual alemana se sustenta en el principio del Príncipe (Führergrundsatz, Führerprincip).

El principio del Príncipe implica esta triple significación: 1), la unidad de Poder en la Administración; 2), compenetración del Führer con la Comunidad que representa; 3 ), unidad en la persona que ordena, pues no es una pluralidad de personas ni una voluntad colegiada, sino que el Poder está representado por una sola persona (2).

Esta idẹa del principio del Führer inspira toda la organización política y administrativa de Alemania. Reza, por lo tanto, para la Administración municipal, igual que para las Administraciones superiores: un mando único representado por una sola persona, compenetrada con el pueblo, que sustancialmente encarna el Partido.

Este órgano soberano dentro de las funciones municipales es el Burgomaestre, de quien dependen todos los funcionarios y servidores municipales (3).

Además de este principio de unidad, que lleva anejo el de respon-

palabras: “El Magisrat, verdadero Comité ejecutivo, es un Cuerpo compuesto del Burgomaestre y de varios miembros-Stadträte o Schoffen. En la constitución de este organismo se señala la característica del gobierno de la ciudad. como régimen técnico; lo componen dos clases de miembros, unos retribuidos, y son verdaderos funcionarios designados en atención a su competencia, y otros gratuitos. El numero total de miembros varía, fijándose en cada caso por Decreto local; al menos un tercio de los miembros debe ser de los no retribuidos. Los retribuídos se designan por doce años, salvo en algunas ciudades, que lo son de por vida; los miembros no retribuidos son elegidos por seis años, renovándose por mitad cada tres. La designación de los retribuidos ha de ser por la autoridad superior; no necesitan ser residentes; con frecuencia se buscan èn otras ciudades. Lo que se desea es el funcionario competente para dirigir un servicio: la hacienda, la enseñanza, las obras públicas, etc., y debe demostrar su preparación profesional. "La ciudad prusiana-escribe Munro-selecciona su alto personal substancialmente según el procedimiento de una bien organizada empresa de negocios", sin consideración de partidos.

(1) Hatscheg, "Lehrbuch des deutschen um Preussischen Werwaltungsrecht”, 1927, págs. 335 y siguientes.

W. Jellinek clasificaba en tres categorías el régimen municipal de Alemania: la 1.7 comprendía un solo organo, colegial; la $2 .{ }^{\circ}$, dos órganos, los dos colegiales, o uno colegial y el otro individual (Burgomaestre); la 3." tres organos, dos colegiados, la Asamblea municipal (StadverornetenversammIung), el Consejo administrativo (Magisrat) y el Burgomaestre (Bürgemeister). "Werwaltungsrecht", páginas 70 y 72 ; Cfr. Bornahk, "Grundriss des Werwaltungsrecht". 1921, páginas 62 y 63; véase Bausen, artículo "Gemeinde" (Staatslexikon)", II, pág. 430.

Heinen, "Gemeinde in Preussen" (Staatslexicon, II, pág. 434).

(2) Maunz, "Verwaltung", págs. 41 y giguientes.

(3) Surén-Loschelder, "Deutsche Gemeindeordnung", 1935, pág. 43. 
sabilidad, estos otros rigen la Administración municipal alemana: a), competencia autonómica; b), las nuevas obligaciones o tareas estatales sólo pueden ser transferidas por la ley; c), los Reglamentos u ordenanzas para ejecutar tales leyes requieren la aprobación del Ministerio del Interior; d), los titulares de los órganos municipales deben gozar de la confianza del Partido. No precisa que pertenezcan a él, pues se han de seleccionar personas técnicas; pero sí que no sean hostiles a la política nacional-socialista, ya que el Partido, si no es un elemento súperestatal, lo parece en cuanto que su savia debe vitalizar los órganos estatales y locales.

En el régimen imperante, o sea el de la ley de 30 de enero de 1925, que tiene su precedente en la ley municipal prusiana de 15 de diciembre de 1933, al acrecentarse jurídicamente el Poder central frente a los Países, era lógico que ocurriera el mismo fenómeno frente a los Municipios, y así, el órgano individual, personal, es el Burgomaestre (Alcalde) —el Superburgomaestre (Oberbürgermeister) para las grandes ciudades-, en el que se van a concentrar las facultades que compartía antes con el Magisrat y el Consejo municipal, bajo su exclusiva responsabilidad. Es designado y separado, tratándose de las ciudades de círculo urbano de más de 100.000 habitantes, por el Ministro del Interior; los que pertenecen a los demás círculos urbanos, por el Comisario del Reich; los Presidentes o Alcaldes de las ciudades de círculos rurales, la autoridad gubernativa provincial, y los de los demás Municipios, por la autoridad gubernativa inferior, a propuesta de los Delegados del Partido, que se tramita por autoridades administrativas intermedias (8, 32 a 41).

Otros órganos municipales, los Adjuntos, se erigen para sustituir y auxiliar a los Alcaldes, sin merma de las funciones de éstos, por delegación; por tanto, designados también por autoridades gubernativas, también a propuesta del Delegado del Partido, oído el Burgomaestre o Alcalde; y los Consejeros, para asesorarle e informarle a su instancia u obligatoriamente, pero sin poder decidir, con facultades ejecutorias, como el antiguo Consejo municipal, designados por Ios Alcaldes a propuesta del Delegado del Partido. Obsérvese la semejanza funcional que guarda este órgano con la Consulta italiana. El número de Consejeros varía, según la categoría del Municipio, de 12 a 36.

Los Delegados del Partido no forman parte del Consejo municipal, pero pueden coparticipar de las funciones asesoras de los Burgomaestres.

Las atribuciones de los Alcaldes son totales en materia edilicia, 0 
que pertenecía anteriormente a los órganos colectivos edilicios, extendiendo su competencia a las funciones delegadas del Poder central (1).

Repetimos que no se precisa pertenecer al Partido nacional-socialista para pertenecer a la Administración municipal; pero se requiere en todo caso gozar de su confianza. Es aquí donde mejor se deja de manifiesto, no que los órganos riel Partido lo sean de la Administración local, ni que los órganos del Partido sean órganos de jerarquía de la Administración local; pero sí que el Partido, como tal, tenga una supremacía o jerarquía local, que a veces hace pensar que es un instrumento de vida superestatal, o que los titulares de los órganos del Estado, y sobre todo de la Administración local, deben supeditar los intereses locales a los de la concepción ideológica del Partido nacional-socialista.

\section{c) Portugal (2)}

Las materias sobre organización y funcionamiento municipal en Portugal son objeto de regulación jurídica en el Código administrativo. En este país la codificación administrativa tiene solera, pues data el primer Cuerpo legal de la Administración de 1836.

En la actualidad, se promulgó el de 1936 por decreto de 21 de diciembre, que inserta las leyes números 1.945 y 1.946, aprobadas por la Asamblea nacional, modificando la ley número 1.940, de 3 de abril de mismo año, que ajusta el proyecto del profesor Caetano, de la Universidad de Lisboa, con las observaciones hechas por la Cámara corporativa.

El Código se ha promulgado con un carácter provisional y a título de prueba, a cuyo efecto se designó una Comisión para que examinara la experiencia y efectividad de los textos legales y viera cuáles debieran ser objeto de modificación, supresión o agregación.

Resultado del estudio fué la reforma del Código, aprobándose el 31 de diciembre pasado el texto definitivo del Código administrativo.

La revisión a que se procedió no alteró substancialmente las líneas generales del texto primitivo, aun siendo importantes las modifica-

(1) Forthoff "Offenthich Recht", 1935, págs. 162 y siguientes; Krüger, "Verfassung und Verwaltung um Grosse deutsche Reich", 1939, pág. 218; Sur€nLoschelder, Ob. cit., págs. 61 y siguientes.-V. Royo y F.-Cavada, "El nuevo Derecho municipal prusiano", Revista de Berecho público, abril ,1934, páginas 3 y siguientes, y "El Partido nacional-socialista alemán obrero y de Administración municipal", Informaciones jurídicas del Ministerio de Justicia, febrero-marzo 1942, pág. 2; Albi, "Principios de organización municiral del Nuevo Estado", Rovista de Gobierno $y$ de Administración local, junio 1941, número 14 , págs. 6,7 y siguientes.

(2) V. Dr. Lopes Dias, "Código administrativo". Lisboa, 1941. 
ciones introducidas y notable el acrecentamiento de las disposiciones, visto que los artículos pasaron de 712 a 861.

Fué mantenida la división administrativa en feligresías, concejos y provincias, corrigiéndose ligeramente la clasificación de los $\mathrm{Mu}$ nicipios, y se revisó la materia relativa a la composición y atribuciones de los concejos municipales, que comprenden los de Lisboa y Oporto, Municipios urbanos-de primera, segunda y tercera clase- y $\mathrm{Mu}$ nicipios rurales (artículo primero).

El Código portugués define el concepto como un agregađo de per sonas residentes en circunscripciones municipales con intereses comunes y regidas por órganos comunes.

Realmente, entra lo definido en la definición, pues cabe preguntar qué es circunscripción municipal, y se dirá: el término donde el concejo ejerce jurisdicción.

Aunque adolezca del defecto apuntado, obsérvese que adquiere un carácter naturál el concejo. Será, pues, la asociación de personas comprendidas en un determinado círculo jurisdiccional, con cierta afinidad de intereses.

El Municipio concentra todas las funciones de carácter local, aun aquellas que tienen relación con servidores del Estado, pues se procura sea un órgano totalitario funcional, si bien al lado de los órganos de Administración: Consejo municipal, Cámara municipal y Presidente de la Cámara municipal; para el asesoramiento técnico funcionan los siguientes órganos municipales consultivos: la Comisión municipal de Higiene, la Comisión municipal de Arte y Arqueología, la Comisión veterinaria concejil, la Comisión municipal de Turismo, los gremios y sindicatos nacionales y cualesquiera otros organismos por la Cámara municipal. (art. 94).

Debo advertir que los Concejos en Lisboa y Oporto no tienen Consejo municipal, sin duda para darles una mayor eficacia administrativa, ya que los presidentes, como si dijéramos, los alcaldes, tienen funciones de gerencia, o sea, casi todas las atribuciones de las Cámaras municipales, es decir, aquellas que tienen un carácter estrictamente administrativo, o las administrativas de menor envergadura.

Los Consejos municipales de los Municipios portugueses, con excepción de Lisboa y Oporto, según ya hemos expuesto, se componen del Presidente de la Cámara (o Alcalde), de los representantes de las feligresías del Consejo, hasta cuatro como máximo, y de representaciones de organizaciones benéficas sindicales, Casas del Pueblo o de cualquier otro organismo corporativo de carácter patronal o productor. 
A estas representaciones netamente corporativas, de índole politica o social, se sumaron dos mayores contribuyentes por territorial, rústica, en los Concejos rural, o por territorio urbano o rústico, en los urbanos que residieran precisamente en el Concejo.

Las funciones de los Concejos son estrictamente electivas (de los vocales de las Cámaras municipales, llamadas veedores), de contrul, de dirección general de la política municipal, y financiera (aprobación de presupuesto ordinario y extraordinario, recargos a las contribuciociones del Estado, etc.).

La Cámara se integra por el Presidente, por un número de vocales que llama la ley veedores (concejales), de dos a seis, según la categoría de la población, estableciendo tres categorías.

En las Cámaras municipales de Lisboa y Oporto el número de vo. cales municipales llega a doce, elegidos por las Juntas de feligreses y organismos corporativos del Concejo (arts. 84 y sigs.).

Los presidentes municipales se eligen todos por el Gobierno (artículos 37 y 8 del Código).

La gestión administrativa de los Municipios portugueses, con la excepción de Lisboa y Oportō, donde, como compete al Presidente, corresponde a las Cámarras municipales, reservándose el Presidente la preparación de asuntos, la ejecución de los acuerdos de las Cámaras, la inspección de los servicios municipales, la representación de las Cámaras en general y, sobre todo, en juicio y algunas iniciales decisiones administrativas en materia de licencias de Policía, con apelación, entonces, a las Cámaras municipales.

\section{d) Francia.}

Venía rigiendo para los Municipios en Francia, al estallar la última guerra mundial, la ley de 5 de abril de 1884 (1), de carácter centralizador desde un punto de vista funcional, democrático desde el punto de vista orgánico.

Los principales órganos eran, con excepción del régimen especial para París y Marsella, los alcaldes ("maires"), uno o varios adjuntos, según la población-colaboradores del Alcalde-, y los Consejos municipales.

La ley de 16 de noviembre de 1940 introdujo algunas modificaciones en la de 1884 respecto del modelo de organización de los $\mathrm{Mu}$. nicipios, singularmente en los grandes, pues para los mayores de dos

(1) Véase su proceso de formación en Morgand, "Le loi municipale". Sobre la nueva ley: Nicolas, "La reforma municipal en Francia". Revista de Gobierno y Administración local, mayo 1941, núm. 13, págs. 13 y siguientes. 
mil habitantes todos los consejeros municipales van a ser nombrados gubernativamente.

Los órganos municipales continúan siendo los mismos (Alcalde, Adjunto, Consejo municipal).

La centralización se acentúa, pues, en esta ley, ya que a la centralización funcional de la ley de 1884 se agrega la orgánica.

Por de pronto, los alcaldes y adjuntos, en poblaciones de dos mil a diez mil habitantes, serán designados por el Prefecto, y en las de más de diez mil habitantes, por el Ministro del Interior; siendo condición esencial para ser Alcalde no sólo ser francés y tener veinticinco años, sino no pertenecer a la raza judía, no siendo indispensable ser vecino del Concejo que se va a regir.

Se reduce el número de consejeros municipales con respecto al asignado en la ley de 1884 (1), sin duda para privar de matiz parlamentario a los Concejos o Ayuntamientos.

Sigue un criterio, para la designación, semejante al que nosotros propugnamos para la designación de concejales gubernativos en España.

Considerábamos que un sector de la colaboración debe gozar de la confianza del Alcalde, para que éste pueda delegar determinadas funciones en los concejales de fiducia; así, pues, habrían de ser designa. dos a su propuesta.

En la ley francesa, para los Municipios de más de cincuenta mil habitantes, designa los consejeros municipales el Ministro del Interior, a propuesta del Prefecto, en lista doble de candidatos de las plazas, previo informe del Alcalde; en los Ayuntamientos de 2.001 a 50.000 habitantes se designarán por el Prefecto, a propuesta del Alcalde, que presentará una lista de doble número de candidatos que plazas a cubrir.

Además, acepta la ley francesa el criterio de representación corporativa o de intereses, que nosotros hemos defendido en nuestra ponencia oficial.

Habrá, pues, representantes de la familia, de las profesiones, de la Beneficencia, e incompatibiliza, en cambio, para ser consejeros a los miembros de la Asamblea Nacional, queriendo obviar el caciqueo político de los parlamentarios a lo Herriot, que reunía el cargo de Alcalde (de Lyón) y de representante de la Cámara de Diputados.

La cesación de funciones de los alcaldes, adjuntos y concejales antes del término señalado en la ley no se hace por las autoridades

(1) Albi: "Principios de organización municipal en el nuevo Estado", Revista de Goblerno y Administración local, mayo 1941, pág. 10. 
o electores que los designaron, así como la disolución de los Consejos, sino por decreto ministerial y por motivos de orden público. Parece, pues, admisible, contra un decreto no motivado o sin alegar dicho motivo, un recurso de exceso de poder por desviación ante el Consejo de Estado.

Los prefectos tienen facultades, en semejantes casos, para suplir o sustituir a los Alcaldes, en tanto los órganos competentes no pro. vean definitivamente.

Coincidente con nuestro punto de vista sobre constitución orgánica, no podemos hacer crítica negativa de la nueva ley francesa; lo que sí podemos decir es que una vez que se centralizan orgánicamente los Municipios y los hilos de la responsabilidad recaen sobre el Poder político del país, podría ya descentralizarse el régimen funcional, que hace hoy de la Administración local francesa una Administración burocratizada y lenta y más sometida a la política que si dependiera la designación de los munícipes del Poder central. Muchos de estos defectos los padecíamos nosotros hasta la vigencia del Estatuto municipal.

\author{
Sabino Alvarez Gendin \\ Catedrático de Derecho Administrativo
}

